\title{
Infrared spectroscopic studies of hydrogen bonding in substituted nitrophenols: substituent and solvent effects
}

\author{
Paula C.M.F. Castilho, Michael R. Crampton and Jack Yarwood * \\ University of Durham, Department of Chemistry, Science Laboratories, South Road, Durham DH1 3LE (UK)
}

(Received 29th November 1991)

\begin{abstract}
A detailed infrared spectroscopic study of the substituted phenols 2-cyano-4,6-dinitrophenol and 4-cyano-2,6-dinitrophenol has been carried out (in several different solvents) in order to investigate the substituent and solvent effects on their intra- and inter-molecular hydrogen bonding properties. In benzene or dichloromethane it is found that both isomers form strong intramolecular hydrogen bonds with the 2-cyano (2CN) isomer having a stronger intramolecular interaction (in accordance with the higher $\mathrm{p} K_{\mathrm{a}}$ ). The 4-cyano $(4 \mathrm{CN})$ isomer shows two distinct $\mathrm{NO}_{2}$ groups and exchange between the two possible hydrogen bonding sites is probably slow on the infrared time-scale. In protic solvents such as methanol the intramolecular hydrogen bonds are broken (more easily for the $4 \mathrm{CN}$ isomer) by intermolecular hydrogen bonding to the solvent. The differential "reactivity" towards methanol may be associated with steric congestion in the $4 \mathrm{CN}$ isomer leading to the forcing of at least one of the $\mathrm{NO}_{2}$ groups out of the aromatic plane. The use of mixed solvents (benzene-methanol) has established that the two hydrogen bonded species are observed together and that a high concentration of methanol is required to drive the equilibrium towards the intermolecular hydrogen bonded species. In dimethyl sulphoxide the behaviour of the two isomers is even more interesting. The $4 \mathrm{CN}$ isomer is ionised to produce the corresponding phenolate. However the $2 \mathrm{CN}$ isomer remains neutral (but highly solvated). We attribute this difference to the requirement for the $4 \mathrm{CN}$ isomer to allow the 2 - and 6- $\mathrm{NO}_{2}$ groups to recover planarity with the aromatic ring. The energy compensation involved in this process is clearly sufficient to break a stronger intramolecular hydrogen bond.
\end{abstract}

Keywords: Infrared spectrometry; Hydrogen bonding; Nitrophenols

A considerable amount of work has been published [1-10] on the spectroscopic study of intramolecular hydrogen bonding in substituted phenols. Attempts have been made, for example, to relate spectral changes to the intramolecular electronic rearrangements $[3,11-13]$ which occur due to the forming and breaking of such (strong) intramolecular interactions. Correlations with the available molecular orbital calculations [5] have also been attempted. Studies up until now have involved NMR and infrared (IR) frequency shifts. Very little work has been published on vibrational band shape and intensity changes caused by intra molecular hydrogen bonding. The most commonly studied compounds in the current con- text are (not surprisingly) the nitrophenols $[1,3,7,9,10]$ and in most IR studies attention has been focussed on the $\mathrm{NO}_{2}$ group vibrations. In this work we have attempted to shed greater light on the electronic and steric factors affecting intramolecular hydrogen bond formation by using compounds containing a nitrile chromophore. Although this obviously complicates the electronic effects on the benzene ring, it also affords another measure of the interactions occurring as a function of substituent position, solvent or concentration. We have also attempted to use the $\tilde{\nu}(\mathrm{OH})$ and $\tilde{\nu}(\mathrm{C}=\mathrm{C})$ (ring) modes of the phenol (where appropriate in a deuterated solvent) to monitor the nature and extent of solvation as a 
TABLE 1

Spectral characteristics of the main infrared bands of 2-cyano-4,6-dinitrophenol (2CN46DNP) and 4-cyano-2,6-dinitrophenol (4CN26DNP)

\begin{tabular}{|c|c|c|c|c|c|c|}
\hline & \multicolumn{3}{|c|}{ 2CN46DNP } & \multicolumn{3}{|c|}{ 4CN26DNP } \\
\hline & $\overline{\bar{\nu}^{\mathrm{a}}}$ & $\Delta \bar{\nu}_{1 / 2} \mathrm{~b}$ & $A^{\mathrm{d}}$ & $\overline{\bar{\nu}^{\mathrm{a}}}$ & $\Delta \bar{\nu}_{1 / 2} b$ & $A^{\mathrm{d}}$ \\
\hline $\begin{array}{l}\bar{\nu}_{a s}\left(\mathrm{NO}_{2}\right) \\
\mathrm{C}_{6} \mathrm{H}_{6}\end{array}$ & $\begin{array}{l}1557 \\
1536\end{array}$ & 16 & 9000 & 1547 & 14 & 18000 \\
\hline $\mathrm{CH}_{2} \mathrm{Cl}_{2}$ & $\begin{array}{l}1559 \\
1540\end{array}$ & 15 & 7600 & 1549 & 14 & 20300 \\
\hline $\mathrm{CD}_{2} \mathrm{Cl}_{2}$ & $\begin{array}{l}1559 \\
1540\end{array}$ & 15 & 7500 & - & - & - \\
\hline $\begin{array}{l}\mathrm{CHCl}_{3} \\
\mathrm{CH}_{3} \mathrm{OH}\end{array}$ & $\begin{array}{r}- \\
1552 \\
1537\end{array}$ & $\overline{27}$ & $54 \overline{0}$ & $\begin{array}{l}1550 \\
1552\end{array}$ & $\begin{array}{l}15 \\
21\end{array}$ & $\begin{array}{l}19200 \\
14000\end{array}$ \\
\hline $\begin{array}{l}\mathrm{CH}_{3} \mathrm{OD} \\
\text { DMSO }\end{array}$ & $\begin{array}{r}- \\
1546\end{array}$ & $\overline{15}$ & 7200 & $\begin{array}{l}1550 \\
e^{-}\end{array}$ & $\begin{array}{l}20 \\
\mathrm{e}\end{array}$ & $\begin{array}{l}16600 \\
e^{-16}\end{array}$ \\
\hline $\begin{array}{l}\tilde{\nu}_{s}\left(\mathrm{NO}_{2}\right) \\
\mathrm{C}_{6} \mathrm{H}_{6}\end{array}$ & 1334 & 13 & 24800 & $\begin{array}{l}1354 \\
1316\end{array}$ & $\begin{array}{l}30 \\
14\end{array}$ & 9700 \\
\hline $\mathrm{CH}_{2} \mathrm{Cl}_{2}$ & 1346 & 14 & 24000 & $\begin{array}{l}1354 \\
1316\end{array}$ & & 9600 \\
\hline $\begin{array}{l}\mathrm{CD}_{2} \mathrm{Cl}_{2} \\
\mathrm{CHCl}_{3}\end{array}$ & $\begin{array}{r}1346 \\
-\end{array}$ & $\begin{array}{l}14 \\
-\end{array}$ & $\begin{array}{r}23000 \\
-\end{array}$ & $\begin{array}{r}- \\
1354 \\
1317\end{array}$ & $\frac{-}{25}$ & 9700 \\
\hline $\mathrm{CH}_{3} \mathrm{OH}$ & 1348 & 15 & 16300 & $\begin{array}{l}1354 \\
1315\end{array}$ & 24 & 8700 \\
\hline \multirow[t]{3}{*}{ DMSO } & 1358 & $\mathrm{e}^{-}$ & e & $\begin{array}{l}1353 \\
1340\end{array}$ & $\begin{array}{l}23 \\
42\end{array}$ & $\begin{array}{r}7600 \\
10300\end{array}$ \\
\hline & \multicolumn{3}{|c|}{ 2CNDNP } & \multicolumn{3}{|c|}{ 4CNDNP } \\
\hline & $\overline{\bar{\nu}^{\mathbf{a}}}$ & $\Delta \bar{\nu}_{1 / 2}{ }^{\mathrm{b}}$ & $A^{\mathrm{c}}$ & $\overline{\bar{\nu}^{a}}$ & $\Delta \bar{\nu}_{1 / 2} \mathrm{~b}$ & $A^{\mathrm{c}}$ \\
\hline \multicolumn{7}{|l|}{$\tilde{\nu}(C N)$} \\
\hline $\begin{array}{l}\mathrm{C}_{6} \mathrm{H}_{6} \\
\mathrm{CH}_{2} \mathrm{Cl}_{2}\end{array}$ & $\begin{array}{l}2239 \\
2249\end{array}$ & $\begin{array}{l}10 \\
12\end{array}$ & $\begin{array}{l}160 \\
200\end{array}$ & $\begin{array}{l}2238 \\
2240\end{array}$ & $\begin{array}{l}11 \\
12\end{array}$ & $\begin{array}{l}180 \\
180\end{array}$ \\
\hline $\mathrm{CD}_{2} \mathrm{Cl}_{2}$ & 2242 & 10 & 200 & - & - & - \\
\hline $\mathrm{CHCl}_{3}$ & - & - & - & 2241 & 14.5 & 300 \\
\hline $\mathrm{CH}_{3} \mathrm{OH}$ & 2241 & 13 & 220 & $\begin{array}{l}2238^{\mathrm{f}} \\
2224^{-1}\end{array}$ & 24 & 250 \\
\hline $\mathrm{CH}_{3} \mathrm{OD}$ & - & - & - & $\begin{array}{l}2238^{f} \\
2224^{-1}\end{array}$ & & \\
\hline DMSO & 2217 & 12 & 500 & 2213 & 12 & 550 \\
\hline \multicolumn{7}{|l|}{$\tilde{\nu}(C=C)$} \\
\hline $\begin{array}{l}\mathrm{C}_{6} \mathrm{H}_{6} \\
\mathrm{CH}_{2} \mathrm{Cl}_{2}\end{array}$ & $\begin{array}{l}1617 \\
1617\end{array}$ & $\begin{array}{l}18 \\
18\end{array}$ & $\begin{array}{l}10700 \\
10500\end{array}$ & $\begin{array}{l}1637 \\
1640\end{array}$ & $\begin{array}{l}14 \\
13\end{array}$ & $\begin{array}{l}7000 \\
7400\end{array}$ \\
\hline $\mathrm{CD}_{2} \mathrm{Cl}_{2}$ & 1617 & 18 & 10500 & - & - & - \\
\hline $\mathrm{CHCl}_{3}$ & - & - & - & 1639 & 14 & 8300 \\
\hline $\mathrm{CH}_{3} \mathrm{OH}$ & 1616 & 27 & 7200 & 1635 & 27 & 7900 \\
\hline $\mathrm{CH}_{3} \mathrm{OD}$ & - & - & - & 1634 & 24 & 8900 \\
\hline DMSO & 1612 & 25 & 14500 & $\begin{array}{l}1635 \\
1616\end{array}$ & 33 & 17800 \\
\hline
\end{tabular}

$\overline{\mathrm{a}} \bar{\nu}$ in $\mathrm{cm}^{-1} \pm 1 .{ }^{\mathrm{b}} \Delta \bar{\nu}_{1 / 2}$ in $\mathrm{cm}^{-1} \pm 1 .^{\mathrm{c}} A$ in $\mathrm{dm}^{3} \mathrm{~mol}^{-1} \mathrm{~cm}^{-2} \pm 10 .{ }^{\mathrm{d}} A$ in $\mathrm{dm}^{3} \mathrm{~mol}^{-1} \mathrm{~cm}^{-2} \pm 100 .{ }^{\mathrm{e}}$ Several unresolved bands in this region. ${ }^{\prime}$ Two bands. 


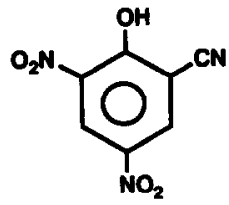

I $\mathrm{pK}_{\mathrm{a}}=1.14$

2CN46DNP

2-CN-4,6-dinitrophenol

Scheme 1.

function of environment. The compounds of interest for this study are shown in Scheme 1. Our interest in these compounds arose from our related kinetics study [14] on the dealkylation of ring activated alkyl aryl ethers in DMSO to produce the corresponding phenolate. It was the differences in IR spectra caused by such ionisation in DMSO which led us to a more detailed study of the corresponding phenols. As far as we are aware, detailed IR spectra of these materials have not been published previously. Furthermore, they give an interesting and instructive insight into the subtleties of electron donating/withdrawing power of $\mathrm{NO}_{2}$ and $\mathrm{CN}$ groups at different positions relative to the $\mathrm{OH}$ group. Comparison of spectra behaviour with and without hydrogen bonding was achieved by using the corresponding anisoles, 2-cyano-4,6-dinitroanisole (2CN46DNA) and 4-cyano-2,6-dinitroanisole (4CN26DNA).

\section{EXPERIMENTAL}

4-Cyano-2,6-dinitrophenol was prepared by the reaction of 4-cyanophenol with fuming nitric acid at room temperature for $24 \mathrm{~h}$. On dilution with iced water, yellow crystals were formed which were dissolved in methanol, dried with $\mathrm{MgSO}_{4}$ and recrystallised twice to give pale cream needles (m.p. $=134-136^{\circ} \mathrm{C}$ ).

2-Cyano-4,6-dinitrophenol was prepared in three stages from 2-cyanochlorobenzene. Nitration with fuming nitric acid, was followed by reaction with $\mathrm{NaOH}$ to yield 2-cyano-4-nitro- phenol. Further nitration gave the desired compound. It was recrystallised from methanol to give pale cream plates (m.p. $=180^{\circ} \mathrm{C}$ ).

IR measurements were performed (with integrated mode 4) with a PE580B instrument. This gives a resolution between 4 and $1 \mathrm{~cm}^{-1}$ over the region examined. Spectra were recorded using freshly prepared solutions in cells of previously determined thickness (typically 6-25 $\mu \mathrm{m}$ ) with calcium fluoride windows. The same cell was first used to record the spectrum of the respective solvent or mixture of solvents under identical conditions and spectral subtraction was then performed to remove the solvent spectrum. Data were transferred to an IBM PC for further analysis and are reported here in dimensionless absorbance units: $\log \left(I_{0} / I\right)$.

\section{RESULTS AND DISCUSSION}

The two isomeric cyano-dinitrophenols have been studied in a variety of solvents and mixed solvent systems in order to elucidate the species present under different environmental conditions. Table 1 summarises the band parameters found for a range of solvents. The $\tilde{\nu}(\mathrm{OH})$ band parameters are not tabulated here but alluded to below. In non-polar aprotic solvents it is wellknown [1,6-8] that $o$-nitrophenols form strong intramolecular hydrogen bonds. The spectra of both compounds in dichloromethane are shown in Fig. 1 in the $\tilde{\nu}(\mathrm{OH})$ region. The only $\tilde{\nu}(\mathrm{OH})$ band observed is that in the $3100-3200 \mathrm{~cm}^{-1}$ region showing (a) that only intramolecular hydrogen bonds are present, (b) that there are only negligible "free" phenol $\mathrm{OH}$ groups (the equilibrium constant for the complexation is large). (Sharper $\tilde{\nu}(\mathrm{CH})$ bands are, of course, found in the $3100 \mathrm{~cm}^{-1}$ region). The 4CN26DNP isomer shows a greater hydrogen bonding shift than the 2CN46DNP implying that the "acidity" of the former compound is greater (as is indicated by the $\mathrm{pK}_{\mathrm{a}}$ values shown in Scheme 1). The 4CN26DNP $\tilde{\nu}(\mathrm{OH})$ band is also broader $\left(\Delta \bar{\nu}_{1 / 2}\right.$ $=195 \mathrm{~cm}^{-1}$ as compared with $\Delta \bar{\nu}_{1 / 2}=125 \mathrm{~cm}^{-1}$ for the 2CN46DNP band). The origin of this extra width is unclear. It should be noted, how- 


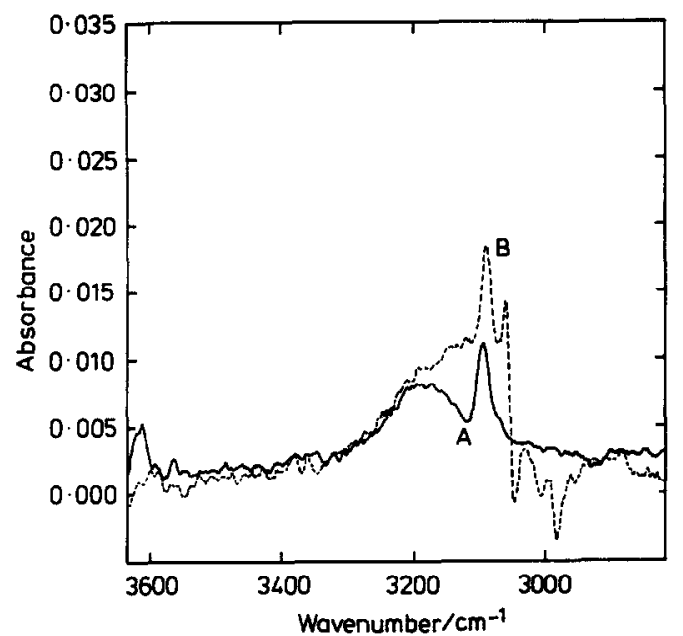

Fig. 1. Comparison of $\tilde{\nu}(\mathrm{OH})$ bands of (A) $2 \mathrm{CN} 46 \mathrm{DNP}$ and (B) $4 \mathrm{CN} 26 \mathrm{DNP}$ in dichloromethane.

ever, that for the 4CN26DNP an intra-molecular hydrogen bond is possible in principle to either of the ortho-nitro groups. Since the interaction is very strong it seems unlikely that exchange occurs between the two $\mathrm{NO}_{2}$ groups on the IR time scale but a contribution from exchange broadening $[15,16]$ cannot be completely ruled out. This would be the equivalent of a delocalised hydrogen bond [11].

There is some evidence $[11,13]$ that steric factors contribute to the apparently very large hydrogen bond strength in these two cyanodinitrophenols. This is because of the bulkiness of the two ortho-nitro groups which may hinder free rotation about the $\mathrm{C}-\mathrm{O}$ bond and therefore enhance interaction of the $\mathrm{OH}$ group with one of the $o-\mathrm{NO}_{2}$ groups, the other $o-\mathrm{NO}_{2}$ group being twisted out of the aromatic ring plane [8]. Nevertheless, electronic factors must also be important, especially in the origin of the difference, between the two isomers. $o-\mathrm{NO}_{2}$ and $p-\mathrm{NO}_{2}$ groups are both expected to increase the $\pi$-electron conjugation between the $\mathrm{OH}$-group and the ring, thereby raising the rotational barrier about the $\mathrm{C}-\mathrm{OH}$ bond. However, $\mathrm{o}-\mathrm{NO}_{2}$ groups are expected to be more effective in doing so. This may account for the enhanced acidity of the 4CN26DNP isomer since the $\mathrm{OH}$ group is rigidly held in the cis-con-<smiles></smiles>

Scheme 2.

formation. The effect of an $o-\mathrm{NO}_{2}$ substituent is to redistribute the $\pi$-electron charge on the $\mathrm{OH}$ oxygen atom as shown in Scheme 2. This leads to an increase in both the $\pi$-donor power of the $\mathrm{OH}$ group and the $\pi$-acceptor ability of the $\mathrm{NO}_{2}$ group. Another electron with drawing group in ortho- or para-positions may well reinforce this redistribution to enhance the $\mathrm{OH}$ electron donation ability to the ring (and hence stabilise the intramolecular hydrogen bond). It is certainly true that the $\tilde{\nu}(\mathrm{OH})$ shifts for 2,4-dinitrophenols and 2,6-dinitrophenol DNP are less [11] than those for the cyanonitrophenols studied here. The ortho- or para-CN group therefore seems to increase the acidity. However, the $\tilde{\nu}(\mathrm{OH})$ band width is greater for the nitrophenols, so the nitrile group clearly has a particular electronic effect on the intramolecular interaction.

In non-polar solvents the $\tilde{\nu}(\mathrm{CN})$ band is remarkably insensitive to substituent position or, indeed (Table 2) to the presence or absence of intramolecular hydrogen bonding. Comparison of the spectra of phenol and anisole (Fig. 2) show that they are almost identical (and nearly Gaussian in shape). The band frequency seems to de-

TABLE 2

$\tilde{\nu}(\mathrm{CN})$ band positions as a function of the number of nitrogroup substituents

\begin{tabular}{ll}
\hline Compound & $\tilde{\nu}(\mathrm{CN})\left(\mathrm{cm}^{-1}\right)$ \\
\hline 2-CN-4,6DNP & 2239 \\
2-CN-4,6DNA & 2240 \\
4-CN-2,6DNP & 2238 \\
4-CN-2,6DNA & 2240 \\
2-CN-4-nitrophenol & 2233 \\
2-CN-4-nitroanisole & 2234 \\
4-CN-phenol & 2225 \\
\hline
\end{tabular}




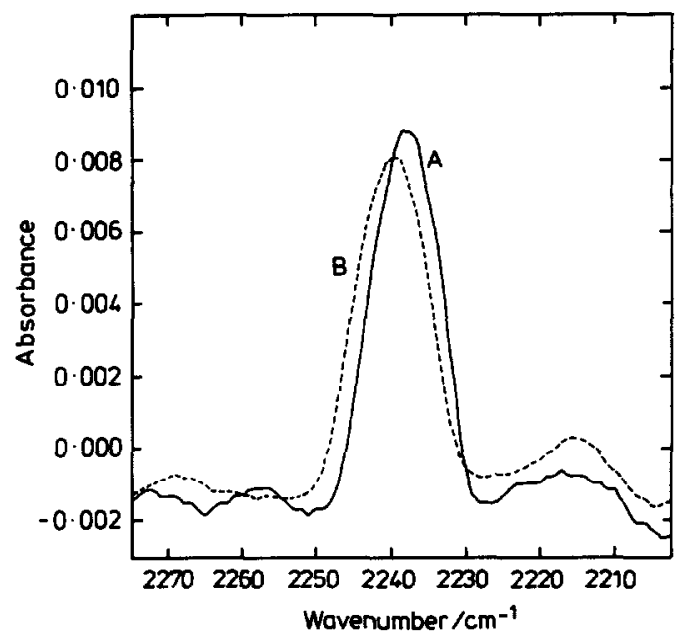

Fig. 2. Comparison of $\bar{\nu}(\mathrm{CN})$ bands of (A) $4 \mathrm{CN} 26 \mathrm{DNP}$ and (B) 4CN26DNA in benzene.

pend on the number of nitro group substituents increasing as the number of substituents increases as shown in Table 2 . The intensity of this band (which is sensitive to hydrogen bond formation [17]) also remains constant for cyanonitrophenols but increases by a factor of 10-15 for $p$-CN-phenol. Such effects are associated with the degree of conjugation of the nitrile group with the aromatic ring. The interaction of a $\pi$-donor such as $\mathrm{OH}$ or $\mathrm{OCH}_{3}$ with a $\pi$-acceptor such as $\mathrm{NO}_{2}$ results in a reduction in the amount of $\sigma$ and $\pi$ charge transfer from the ring to the $\mathrm{CN}$ group. So, for example, the contribution of resonance form (2) (Scheme 3) would be minimal for $\mathrm{Y}=\mathrm{NO}_{2}$ but would be important for $p$ cyanophenol where there is no competition with other acceptor groups.. The net increase in negative charge on the $\mathrm{CN}$ group will lead $[17,18]$ to (a) a frequency shift to the red, because electron<smiles>[Y]c1cc(C#N)cc([N+](=O)[O-])c1O</smiles>

(1)

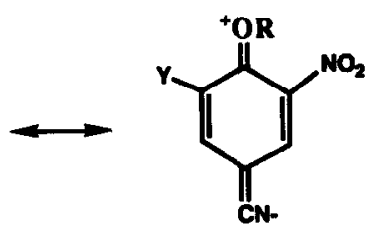

(2)
Scheme 3 .
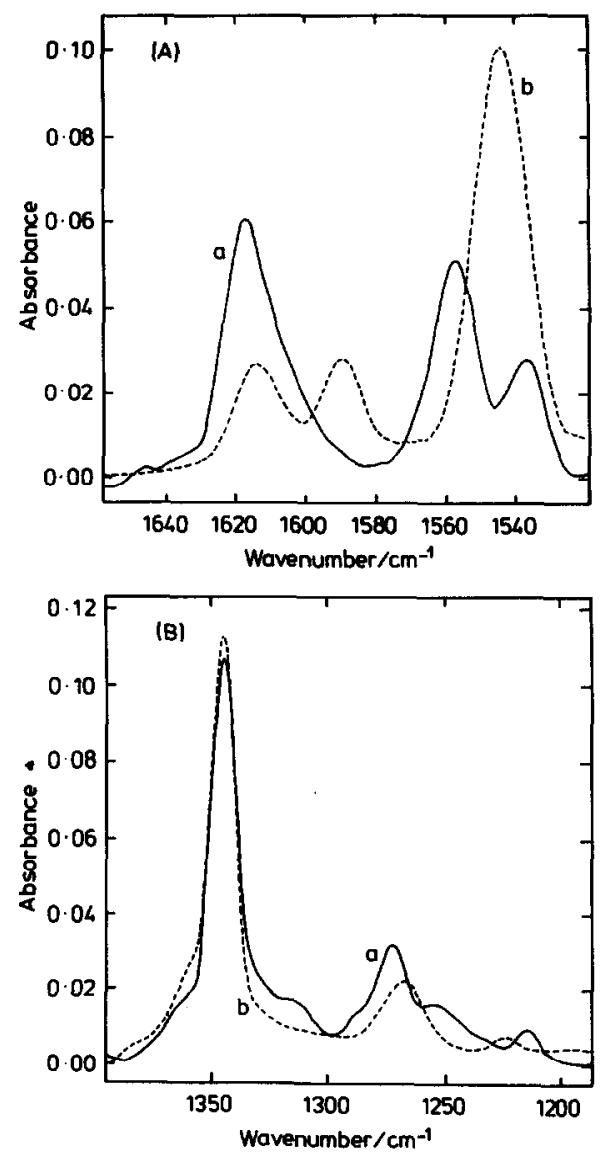

Fig. 3. Comparison of $\tilde{\nu}\left(\mathrm{NO}_{2}\right)$ bands of (a) $2 \mathrm{CN} 46 \mathrm{DNP}$ with those of (b) 2CN46DNA in benzene, (A) the $\tilde{\nu}_{\mathrm{a}}\left(\mathrm{NO}_{2}\right)$ region, (B) the $\bar{\nu}_{s}\left(\mathrm{NO}_{2}\right)$ region.

density goes into antibonding orbitals, (b) an increase in intensity due to dynamic intramolecular charge transfer $[13,19]$. The behaviour of our spectra in this region shows clearly that hydrogen bonding has little or no influence on the $\mathrm{CN}$ bond electronic structure and that (for the 2CN46DNP isomer) the CN group is not involved in hydrogen bonding. Intramolecular hydrogen bonding thus affects only the region of the molecule associated with the $\mathrm{OH}$ and $o-\mathrm{NO}_{2}$ groups (Scheme 2).

The nitro group $\tilde{\nu}\left(\mathrm{NO}_{2}\right)$ region is probably the most interesting spectroscopically. Figures 3-5 show the antisymmetric and symmetric stretching bands, $\tilde{\nu}_{\mathrm{a}}\left(\mathrm{NO}_{2}\right)$ and $\tilde{\nu}_{\mathrm{s}}\left(\mathrm{NO}_{2}\right)$, of the two com- 
pounds under investigation along with the corresponding bands of trinitrophenol (TNP) for comparison. The spectra of the corresponding anisoles are also shown for reference. The data are summarised in Table 3. For the 2CN46DNP isomer the two nitro groups are formally different and two sets of bands would be expected. For the phenol in benzene one set should correspond to an intramolecularly hydrogen bonded $\mathrm{NO}_{2}$ group. A survey of the (old) literature [12,20,21] seems to show (Table 4) that hydrogen bonding causes a small red shift $\left(\approx 7 \mathrm{~cm}^{-1}\right)$ of $\tilde{\nu}_{\mathrm{s}}\left(\mathrm{NO}_{2}\right)$ band and a large blue shift $\left(\approx 20-30 \mathrm{~cm}^{-1}\right)$ of the $\tilde{\nu}_{\mathrm{as}}\left(\mathrm{NO}_{2}\right)$ band. Such shifts may be understood in terms of differing degrees of resonance on hydrogen bond-
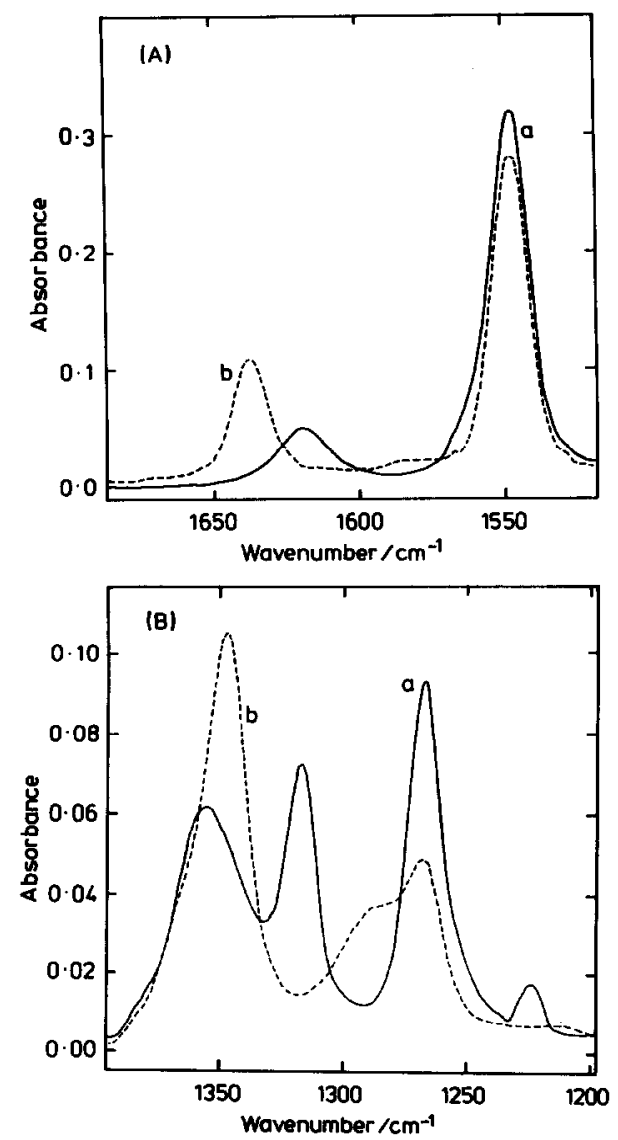

Fig. 4. Comparison of $\bar{\nu}\left(\mathrm{NO}_{2}\right)$ bands of (a) 4CN26DNP with hose of (b) 4CN26DNA in benzene, (A) the $\tilde{\nu}_{a}\left(\mathrm{NO}_{2}\right)$ region, B) the $\tilde{\nu}_{\mathrm{s}}\left(\mathrm{NO}_{2}\right)$ region.
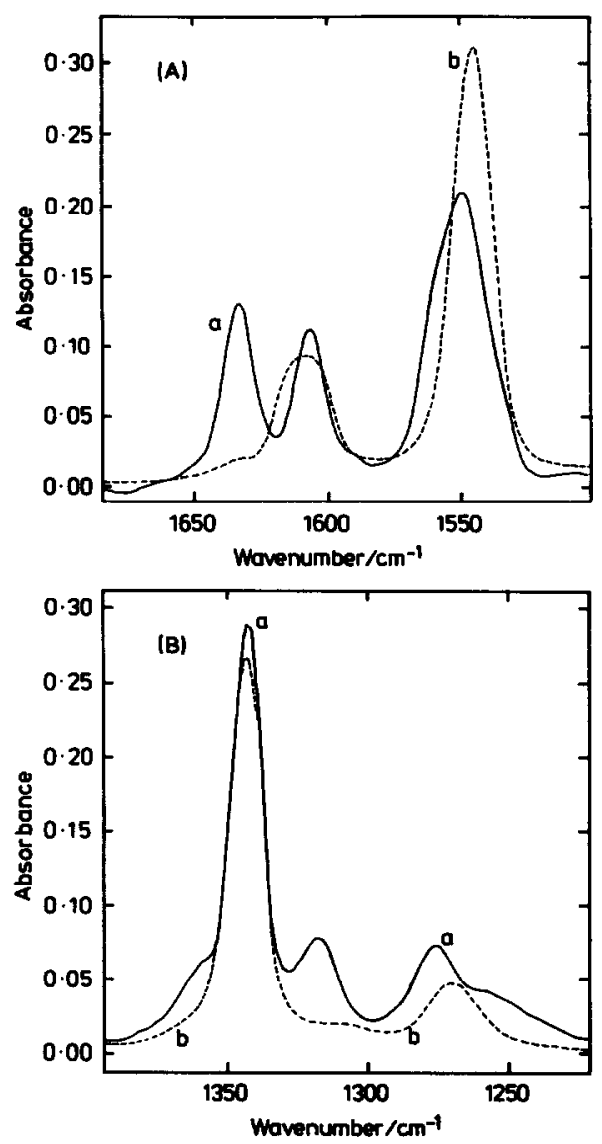

Fig. 5. Comparison of $\bar{\nu}\left(\mathrm{NO}_{2}\right)$ bands of (a) TNP with those of (b) TNA in benzene, (A) the $\tilde{\nu}_{\mathrm{a}}\left(\mathrm{NO}_{2}\right)$ region, (B) the $\tilde{\nu}_{\mathrm{s}}\left(\mathrm{NO}_{2}\right)$ region.

ing and the change in planarity of the $\mathrm{NO}_{2}$ group with the ring. Thus, the vibrational bands of the $p-\mathrm{NO}_{2}$ and $o-\mathrm{NO}_{2}$ groups may be assigned (Fig. 3) quite straightforwardly (Table 3). Although the anisole does not show two separate sets of $\tilde{\nu}\left(\mathrm{NO}_{2}\right)$ bands, the phenol does. In the case of the $4 \mathrm{CN} 26 \mathrm{DNP}$ isomer, only one $\tilde{\nu}_{\mathrm{as}}\left(\mathrm{NO}_{2}\right)$ band is observed (Fig. 4A) with some narrowing on going to the phenol (Table 3). However, the $\tilde{\nu}_{s}\left(\mathrm{NO}_{2}\right)$ band shows dramatic splitting on going from anisole to phenol and band width of the $\tilde{\nu}_{\mathrm{s}}\left(\mathrm{NO}_{2}\right)$ band increases by $50 \%$. It seems likely that this band broadening is due to hydrogen bonding (and maybe connected with the fact that there are two possible "sites"). However, the trinitro analogues 
TABLE 3

Summary of $\tilde{\nu}\left(\mathrm{NO}_{2}\right)$ band spectral data for the cyanonitrophenols and anisoles studied here (the full half-widths are shown in brackets)

\begin{tabular}{|c|c|c|c|c|c|c|c|}
\hline Compound & $\tilde{\nu}_{\text {as }}$ & $\tilde{\nu}_{\mathrm{s}}$ & $\begin{array}{l}A_{\mathrm{a}} / A_{\mathrm{s}} \\
\text { ratio }\end{array}$ & Compound & $\tilde{\nu}_{\mathrm{as}}$ & $\tilde{\nu}_{\mathrm{s}}$ & $\begin{array}{l}A_{\mathrm{a}} / A_{\mathrm{s}} \\
\text { ratio }\end{array}$ \\
\hline $\mathrm{O}_{2} \mathrm{~N}$ & $1546(19)$ & $\begin{array}{l}1345(13) \\
(1360) \mathrm{sh} ?\end{array}$ & 0.7 & $\mathrm{O}_{2} \mathrm{~N}$ & $\begin{array}{r}1560(o) \\
(13) \\
1536(p)\end{array}$ & $\begin{array}{r}1323 \text { (sh) } \\
\text { (13) } \\
1344\end{array}$ & 0.36 \\
\hline $2 \mathrm{CN} 46 \mathrm{D}$ & & & & 2CN46D & & & \\
\hline $\mathrm{O}_{2} \mathrm{~N}$ & $1548(16)$ & $1347(20)$ & 3.0 & $\Omega_{1}$ & $1550(14)$ & $\begin{array}{l}1320(14) \\
1354(30)\end{array}$ & 1.86 \\
\hline $4 \mathrm{CN} 26 \mathrm{D}$ & & & & $4 \mathrm{CN} 26$ & & & \\
\hline $\mathrm{O}_{2} \mathrm{~N}$ & $1550(18)$ & $1348(14)$ & 1.1 & $\mathrm{O}_{2} \mathrm{~N}$ & $\begin{array}{l}1552(24)(0) \\
(+ \text { two shoulders })\end{array}$ & $\begin{array}{l}(1360 \mathrm{sh}) \\
1325(15) \\
1344(14)\end{array}$ & 0.48 \\
\hline TNA & & & & TNP & & & \\
\hline
\end{tabular}

(Table 3 and Fig. 5) do not appear to show this effect. Although the TNP shows two $\tilde{\nu}_{\mathrm{s}}\left(\mathrm{NO}_{2}\right)$ bands they are both about $\approx 15 \mathrm{~cm}^{-1}$ wide. Except for the extreme broadening in the 4-CN

\section{TABLE 4}

Summary of the steric, electronic and hydrogen bonding processes on the $\tilde{\nu}_{\mathrm{as}}\left(\mathrm{NO}_{2}\right)$ and $\tilde{\nu}_{\mathrm{s}}\left(\mathrm{NO}_{2}\right)$ bands of substituted nitrophenols (numbers give references)

\begin{tabular}{|c|c|c|c|c|}
\hline \multirow[t]{2}{*}{ Type of effect } & \multicolumn{2}{|c|}{$\tilde{\nu}_{a s}\left(\mathrm{NO}_{2}\right)$} & \multicolumn{2}{|c|}{$\tilde{\nu}_{\mathrm{s}}\left(\mathrm{NO}_{2}\right)$} \\
\hline & Freq. & Int. & Freq. & Int: \\
\hline Steric $^{a}$ & 21.20 & $\uparrow_{8}$ & $\uparrow_{8}$ & - \\
\hline Conjugation & $\left.\right|_{21}$ & - & $\mid 6$ & $\uparrow 6$ \\
\hline Hydrogen bonding & $\uparrow_{8}$ & $\prod_{8}$ & 8 & $\uparrow_{8}$ \\
\hline
\end{tabular}

$\mathrm{NO}_{2}$ rotates out of the ring plane $[8,21]$. compound, the phenols show a remarkably consistent frequency pattern with inequivalent $\mathrm{NO}_{2}$ groups in all cases. However, the intensity pattern is quite different. It appears that if there is no $p-\mathrm{NO}_{2}$ group the intensity ratio $A_{\text {ass }} / A_{\text {sym }}$ for these $\tilde{\nu}\left(\mathrm{NO}_{2}\right)$ bands increases dramatically. This is due to a massive intensity increase of the $\tilde{\nu}_{\mathrm{a}}\left(\mathrm{NO}_{2}\right)$ band when the $p-\mathrm{NO}_{2}$ group is removed, presumably due to drastic electronic changes caused by loss of coupling between ortho- and para- $\mathrm{NO}_{2}$ groups.

In polar solvents these compounds are expected to behave in a somewhat different way. In hydrogen bonding solvents (Table 1) such as methanol the possibility of replacing intramolecular hydrogen bonds by their intermolecular counterparts (to the solvent) is obvious. However, there are likely to be more subtle effects such as the (intermolecular) interactions between solvent and the $\mathrm{NO}_{2}$ and/or $\mathrm{CN}$ groups. Unfortunately, we have not been able to examine the $\tilde{\nu}(\mathrm{OH})$ region in detail for phenols in methanol (or other protic solvents) because of rapid exchange with 

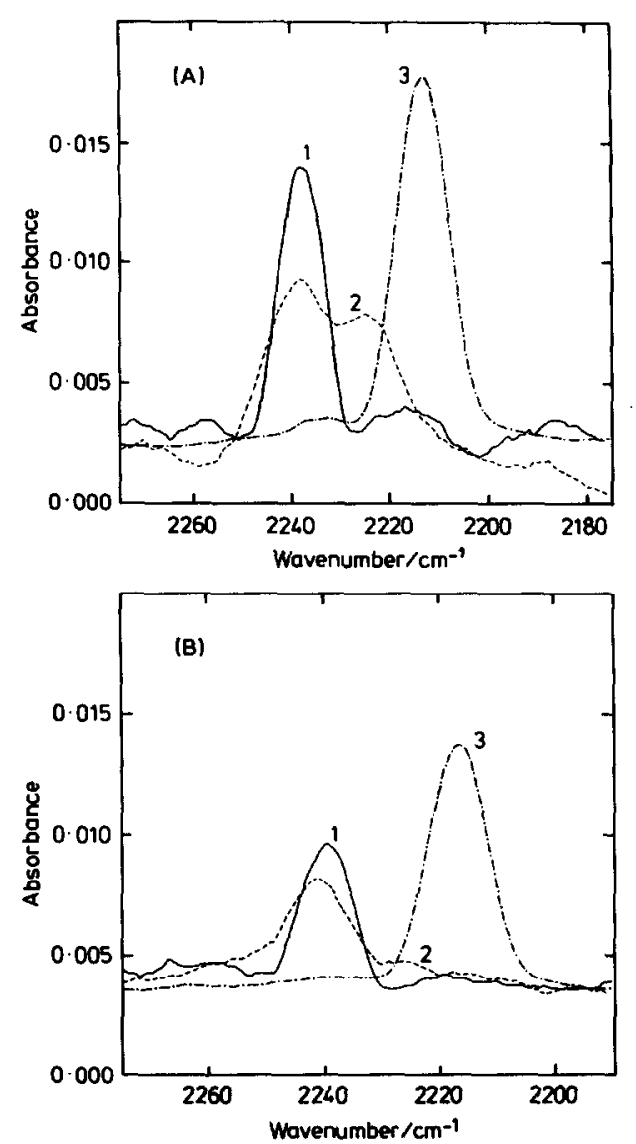

Fig. 6. Comparison of the $\tilde{\nu}(\mathrm{CN})$ band of (A) 4CN26DNP and, (B) 2CN46DNP, in several solvents. (1) Benzene, (2) methanol, (3) dimethyl sulphoxide.

the deuterated solvents. However, the $\tilde{\nu}(\mathrm{CN})$ and $\tilde{\nu}\left(\mathrm{NO}_{2}\right)$ modes have been examined in detail in a variety of media (Table 1 ). We concentrate attention here on the spectra in methanol $(\mathrm{MeOH})$ and dimethyl sulphoxide (DMSO).

The $\tilde{\nu}(\mathrm{CN})$ band shows considerable variation in different solvents. Figure 6 shows that two bands (at 2238 and $2224 \mathrm{~cm}^{-1}$ ) are clearly seen in methanol. One of these is at a position very close to that in benzene. The other is shifted to the red by about $16 \mathrm{~cm}^{-1}$. However, the total intensity seems to be little changed (but is redistributed among two sites?). The same pattern is followed by both isomers in methanol although the "new" site has a much lower intensity for the 2CN46DNP isomer. This site might, at first sight, to be thought<smiles>COCNCc1cc([N+](=O)[O-])cc([N+](=O)[O-])c1P</smiles>

Scheme 4.

due to a hydrogen bonded complex of the type shown in Scheme 4. However, there is much evidence [17] that such interaction causes a change in $\bar{v}(\mathrm{CN})$ to higher frequency so a "blue" rather than a "red" shift would be expected. This shift is connected with a change in polarity of the $\mathrm{CN}$ bond caused by electron donation from the nitrogen lone pair. Another possibility is that the second band is due to ionisation in polar solvents since the cyanonitrophenoxides [21] also have a $\tilde{\nu}(\mathrm{CN})$ band near $2224 \mathrm{~cm}^{-1}$. However, other parts of the spectrum show that this is not the case. For example, Fig. 7 shows that on going to a methanolic solvent the intermolecular hydrogenbonded $\tilde{\nu}(\mathrm{OH})$ band near $3450 \mathrm{~cm}^{-1}$ tends to dominate the spectrum. The equilibrium shown in Scheme 5 therefore gives rise to the two $\tilde{\nu}(\mathrm{CN})$ bands due to "complexed" and "free" $\mathrm{CN}$ groups on the IR time scale. Hydrogen bonds with the $\mathrm{NO}_{2}$ groups are also expected of course (see

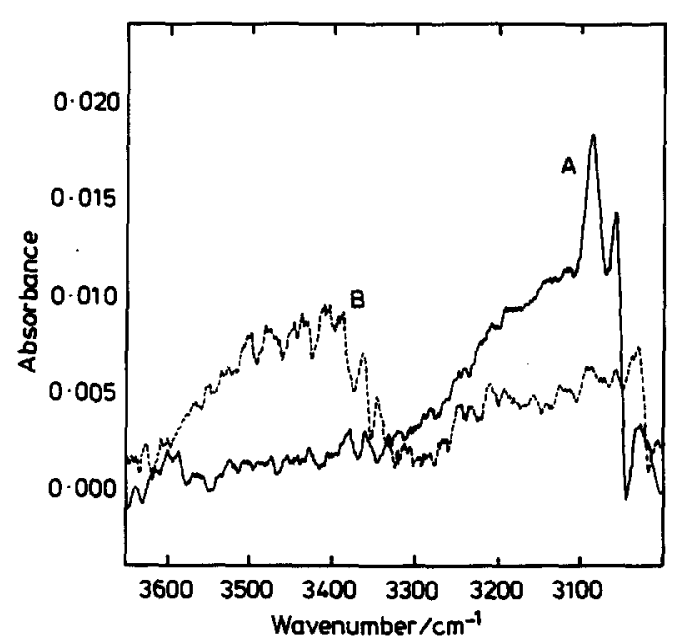

Fig. 7. Comparison of the $\bar{\nu}(\mathrm{OH})$ bands of $4 \mathrm{CN} 26 \mathrm{DNP}$ in (A) benzene and (B) methanol- $d_{4}$. 


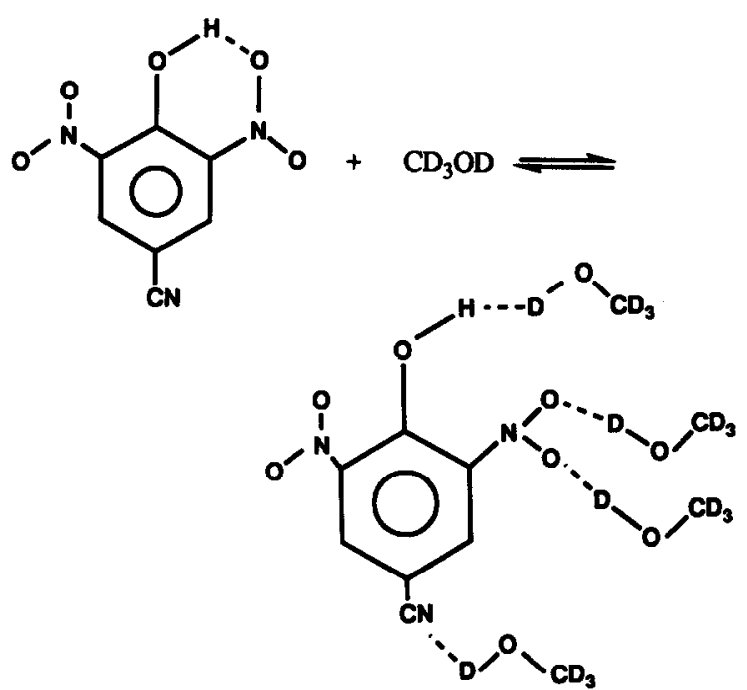

Scheme 5.

below). Furthermore, the aromatic ring modes (except for some broadening in methanol) are not very sensitive (Table 1) to changing from benzene to methanol. We have attempted to quantify this equilibrium for the 4CN26DNP isomer by using a mixed benzene-methanol solvent. Figure 8 shows that, as the mole fraction of methanol in the mixture is raised, the $\tilde{\nu}(\mathrm{CN})$ band at $\approx 2224$

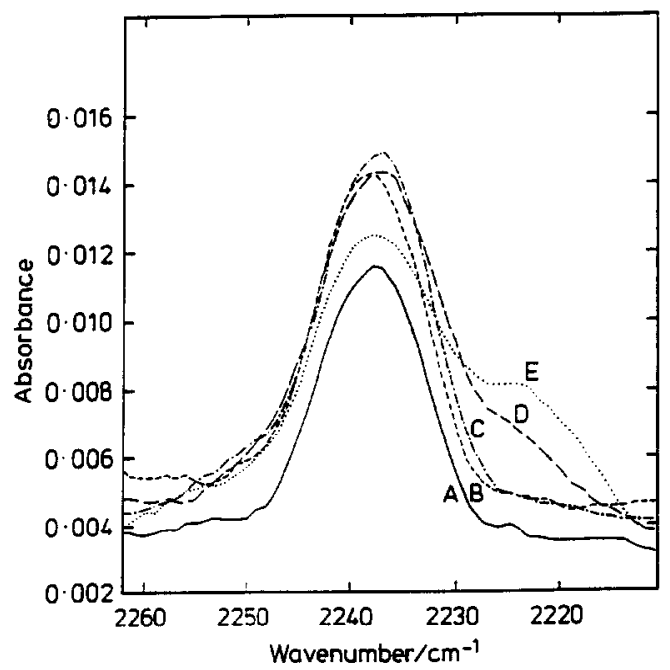

Fig. 8. Variation of $\tilde{\nu}(\mathrm{CN})$ band of $4 \mathrm{CN} 26 \mathrm{DNP}$ in mixtures of benzene and methanol. The methanol mole fractions are (A) 0.04, (B) 0.09, (C) 0.16, (D) 0.50, (E) 0.69 .<smiles>N#Cc1cc([N+](=O)[O-])c(O)c([N+](=O)[O-])c1</smiles><smiles></smiles><smiles>N#Cc1cc([N+](=O)[O-])cc([N+](=O)[O-])c1O</smiles><smiles>CCCCCC</smiles><smiles>[N-]=C=C1C=C([N+](=O)[O-])C=C([N+](=O)[O-])C1=O</smiles>

$\mathrm{cm}^{-1}$ increases in intensity. Quantification is obviously difficult but it is equally clear that quite a large excess of methanol is needed to shift the equilibrium significantly to the right hand side. This maybe due to bridging of the $\mathrm{OH}$ and $\mathrm{NO}_{2}$ groups by one methanol molecule. From Fig. 6 it also appears that the breaking of the intramolecular hydrogen bond appears to be easier for the $4 \mathrm{CN}$ isomer. This process leads to a decrease in the $\mathrm{CN}$ bond order, and must be associated with adjustments in the degree of resonance of the $\mathrm{CN}$ group with the ring (although changes of electronic structure within the ring and the C-O group appear to be minimal). These may arise if the methanol, in breaking the intramolecular hydrogen bond, forces one or both $\mathrm{NO}_{2}$ groups out of the aromatic ring plane. This would reduce $\mathrm{NO}_{2}$ group $\pi$-acceptor ability and cause the $\mathrm{CN}$ group to accept more electron density. In resonance terms this may be represented as shown in Scheme 6 and be less probable in the case of the 2CN46DNP because there is less steric congestion near the $\mathrm{OH}$ group. Such effects ought to be also seen in the spectra of the $\mathrm{NO}_{2}$ group. Examination of Table 1 and Figs. 9 and 10 shows that the pattern of $\tilde{\nu}\left(\mathrm{NO}_{2}\right)$ bands is mostly similar in methanol to what it is in benzene. However, there are some significant differences. For the 4CN26DNP isomer, dissolution in methanol results in the loss of the $\tilde{\nu}_{\mathbf{s}}\left(\mathrm{NO}_{2}\right)$ band at 1316 
$\mathrm{cm}^{-1}$ previously assigned (Table 3 ) to the intramolecularly hydrogen bonded $\mathrm{NO}_{2}$ group (Fig. 9). Figure 11 shows that the two bands show the expected relative intensity change in a benzenemethanol mixture and this confirms the conclusion drawn from the $\tilde{\nu}(\mathrm{CN})$ band analysis. Figure 12 shows that the equilibrium is relatively little affected until the mole fraction of methanol reaches $\approx 0.4$. This phenomenon is related to the replacement of benzene by methanol in the first solvation shell. The same feature may occur for the 2CN46DNP isomer (Fig. 9) but the 1323 $\mathrm{cm}^{-1}$ band is of low intensity and this makes it difficult to be certain. The $\tilde{\nu}_{\mathrm{a}}\left(\mathrm{NO}_{2}\right)$ region is less
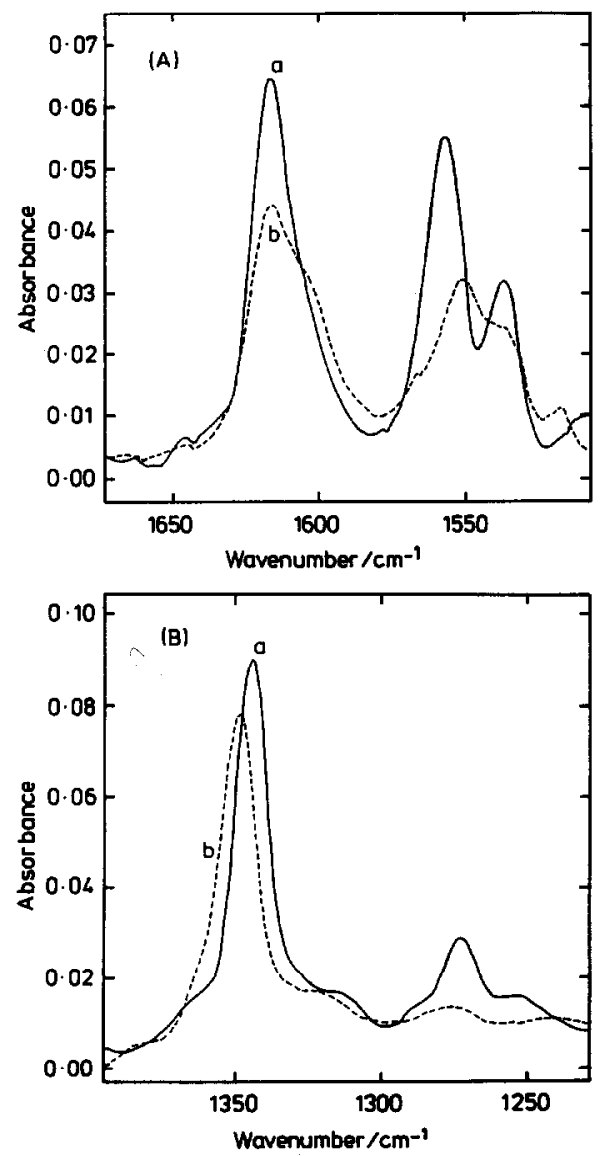

Fig. 9. Comparison of the $\tilde{\nu}_{\mathrm{a}}\left(\mathrm{NO}_{2}\right), \tilde{\nu}_{\mathrm{s}}\left(\mathrm{NO}_{2}\right)$ and ring $\tilde{\nu}(\mathrm{C}=\mathrm{C})$ bands of 2CN46DNP in (a) benzene, (b) methanol. (A) Ring breathing and $\tilde{\nu}_{\text {as }}\left(\mathrm{NO}_{2}\right)$ bands, (B) $\bar{\nu}_{\mathrm{s}}\left(\mathrm{NO}_{2}\right)$ and $\bar{\nu}(\mathrm{C}-\mathrm{O})$ bands.
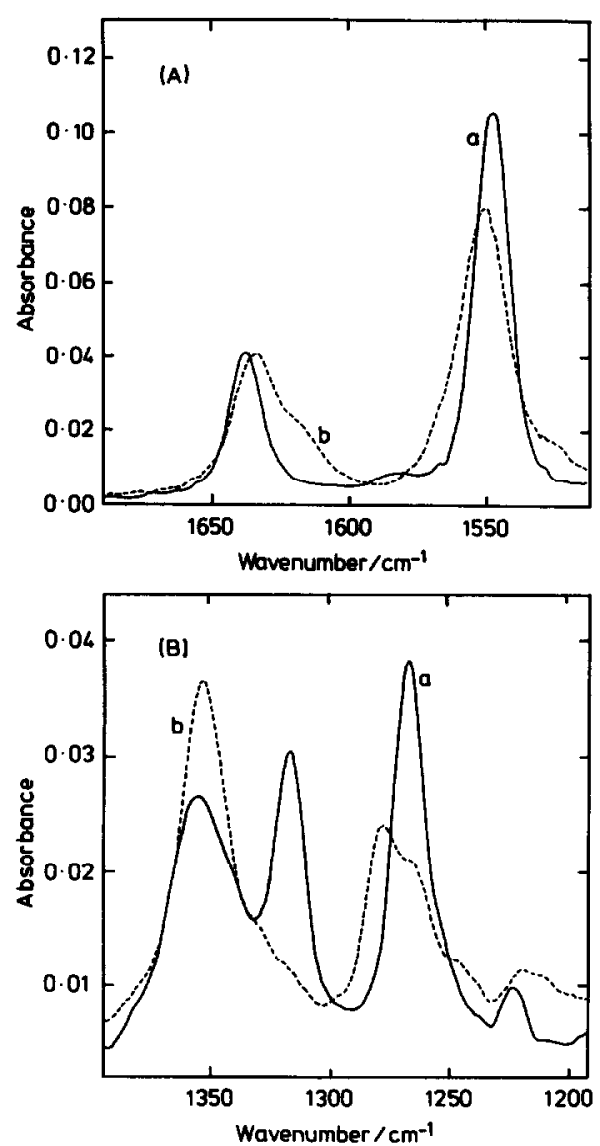

Fig. 10. Comparison of the $\tilde{\nu}_{\mathrm{a}}\left(\mathrm{NO}_{2}\right), \tilde{\nu}_{\mathrm{s}}\left(\mathrm{NO}_{2}\right)$ and ring $\tilde{\nu}(\mathrm{C}=$ C) bands of 4CN26DNP in (a) benzene and (b) methanol. (A) Ring breathing and $\bar{\nu}_{\mathrm{as}}\left(\mathrm{NO}_{2}\right)$ bands, $(\mathrm{B}) \bar{\nu}_{\mathrm{s}}\left(\mathrm{NO}_{2}\right)$ and $\tilde{\nu}(\mathrm{C}-\mathrm{O})$ bands.

definitive but the 2CN46DNP isomer does show a dramatic intensity decrease of the $1546 \mathrm{~cm}^{-1}$ $\left(o-\mathrm{NO}_{2}\right)$ band in methanol. This may also be associated with breaking of the intramolecular hydrogen bond. Interestingly both isomers show two bands in the $1620-1650 \mathrm{~cm}^{-1}$ region in methanol (Figs. 9 and 10) due to an additional ring breathing mode environment.

The behaviour of these molecules in an aprotic, but polar, solvent such as DMSO is even more interesting. In DMSO, the $\tilde{\nu}(\mathrm{OH})$ region for the 2CN26DNP isomer shows only one broad, asymmetric band at $\approx 3380 \mathrm{~cm}^{-1}$. This band (Fig. 13) is due to a strong hydrogen bond formed 
between the phenol and the solvent. This behaviour is very similar to that of $p$-cyanophenol and the interpretation is confirmed by the NMR spectra which show the appropriate down field shifts due to intermolecular hydrogen bonding (as compared with the non-polar solvents). The NMR spectrum of 2CN46DNP in benzene shows spin coupled bands, $J=3 \mathrm{~Hz}$, at $\delta 7.53$ and 8.06 due to the ring hydrogens at $\mathrm{H}_{3}$ and $\mathrm{H}_{5}$ with a band at $\delta 10.7$ due to the hydroxyl proton. In DMSO the ring proton bonds are shifted downfield to $\delta$ 11.9. The differential shifts with charge in solvent for protons $\mathrm{H}_{3}(\delta 0.89)$, and $\mathrm{H}_{5}(0.59)$ shows that the DMSO solvation is influenced by the $2 \mathrm{CN}$ group, the proton $\mathrm{H}_{3}$ showing a larger solvent shift than the $\mathrm{H}_{5}$ proton. The resulting interaction of DMSO at the $\mathrm{CN}$ group should be seen as a shift of the $\tilde{\nu}(\mathrm{CN})$ band. Figure 6 shows that this shift is to about $2220 \mathrm{~cm}^{-1}$. The behaviour of the 4CN26DNP derivative in DMSO is, however, totally different. Figure 14 shows the ${ }^{1} \mathrm{H}$ NMR spectra of this isomer in both benzene- $d_{6}$ and DMSO- $d_{6}$. Although a broad hydrogen bonded $\mathrm{OH}$ signal $(\delta 10.8)$ is observed in $\mathrm{C}_{6} \mathrm{D}_{6}$ no such signal appears in DMSO $d_{6}$ solution. Instead we get a singlet at $\delta 8.26$ and a line at $\delta 7.0$ whose shape is dependent on concentration. The latter is due to species [23] such as $\left[\left(\mathrm{CD}_{3}\right)_{2} \mathrm{SO}-\mathrm{H}\right.$ -

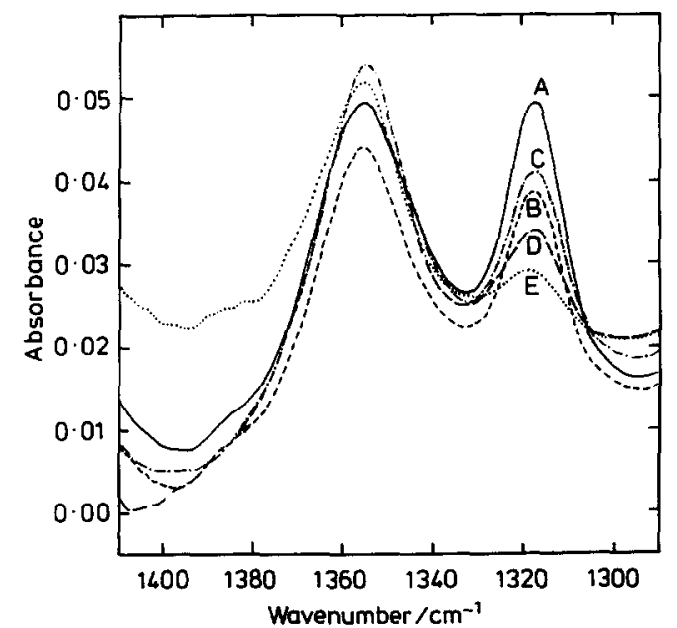

Fig. 11. Variation of $\tilde{\nu}_{s}\left(\mathrm{NO}_{2}\right)$ band of $4 \mathrm{CN} 26 \mathrm{DNP}$ in benzene-methanol mixtures. The mole fractions of methanol are the same as those given for Fig. 8.

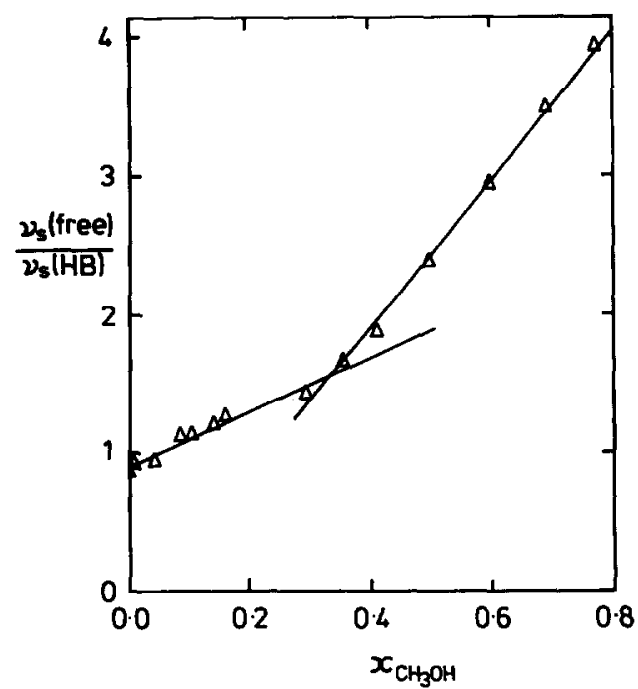

Fig. 12. Variation in the $\tilde{\nu}_{\mathrm{s}}$ (free) $/ \tilde{\nu}_{\mathrm{s}}(\mathrm{HB})$ band height ratio $(R)$, for the $\bar{\nu}_{\mathrm{s}}\left(\mathrm{NO}_{2}\right)$ band of $4 \mathrm{CN} 26 \mathrm{DNP}$ in benzenemethanol mixtures.

$\left.\operatorname{OS}\left(\mathrm{CD}_{3}\right)_{2}\right]^{+}$showing that ionisation has occurred. The IR spectra of the $\tilde{\nu}(\mathrm{CN})$ band also support this assignment. Figure 15 and Table 5 show the data for a mixed solvent of benzene with DMSO. As the proportion of DMSO in the mixture is increased both $\tilde{\nu}(\mathrm{CN})$ bands shift to lower frequency band $B$ shifting faster until in pure DMSO it reaches $\approx 2213 \mathrm{~cm}^{-1}$. This is

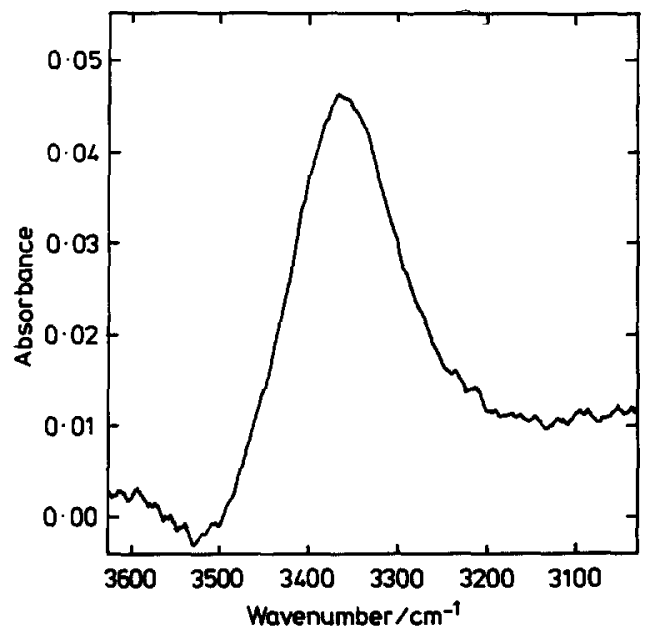

Fig. 13. The broad $\tilde{\nu}(\mathrm{OH})$ band for $2 \mathrm{CN} 46 \mathrm{DNP}$ in DMSO. 
(a)

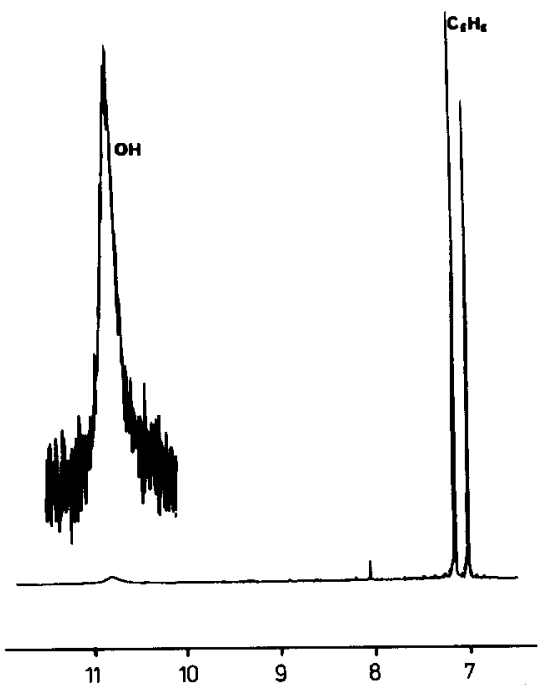

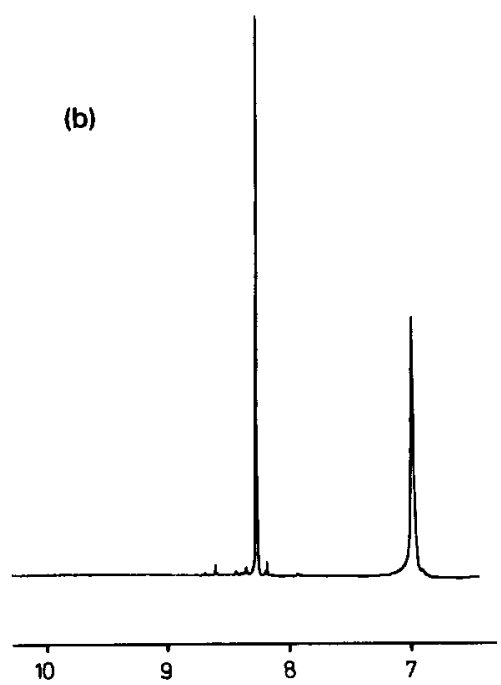

Fig. 14. The ${ }^{1} \mathrm{H}$ NMR spectra of $4 \mathrm{CN} 26 \mathrm{DNP}$ in (a) $\mathrm{C}_{6} \mathrm{D}_{6}$, (b) DMSO- $d_{6}$.

identical with the $\tilde{\nu}(\mathrm{CN})$ band position in $4 \mathrm{CNDNPh}^{-} \mathrm{Na}^{+}[22]$ and confirms that ionisation occurs in DMSO. The $\tilde{\nu}(\mathrm{CN})$ band and $\tilde{\nu}_{\mathrm{s}}\left(\mathrm{NO}_{2}\right)$ band shifts (Table 5) with increasing solvent polarity again reflecting the sort of solvation illustrated in Scheme 7. It appears that the proportion of DMSO molecules in the mixture needs to be high ( $>0.5 \mathrm{mf}$ ) before specific solvation effects are observed. This seems to be especially true for the $\mathrm{NO}_{2}$ groups. The situation is, of course, complicated by the competing effects of solvation and ionisation, there being two solvated species at intermediate DMSO concentrations.

This difference in behaviour between the two cyanonitrophenols is an interesting one. Clearly the $4 \mathrm{CN}$ analogue forms the stronger intramolecular hydrogen bond. However, this is the hydrogen bond which is most easily broken by methanol solvation and it is the $4 \mathrm{CN}$ isomer which is ionised in DMSO. This result is almost certainly associated with steric interactions at the two ortho

\section{TABLE 5}

Infrared bands of 4CN26DNP in solvent mixtures of benzene and DMSO

\begin{tabular}{llllllll}
\hline $\begin{array}{l}\text { Mixture } \\
\text { (mf }\end{array}$ & $\tilde{\nu}(\mathrm{CN})$ & & $\tilde{\nu}$ (ring) & $\tilde{\nu}_{\mathrm{as}}\left(\mathrm{NO}_{2}\right)$ & $\tilde{\nu}_{\mathrm{s} 1}\left(\mathrm{NO}_{2}\right)^{\mathrm{a}}$ & $\tilde{\nu}_{\mathrm{s} 2}\left(\mathrm{NO}_{2}\right)^{\mathrm{b}}$ & $\bar{\nu}(\mathrm{CO})$ \\
\cline { 2 - 6 } & $\boldsymbol{A}$ & $\boldsymbol{B}$ & & & & & \\
\hline 0 & 2239 & - & 1637 & 1547.0 & 1354.5 & 1316.0 & 1267.1 \\
0.01 & 2234.3 & 2219.0 & 1630 & 1547.3 & 1354.7 & 1306.8 & 1268.7 \\
0.06 & 2234.3 & 2219.0 & 1630 & 1547.3 & 1354.7 & 1315.2 & 1267.0 \\
0.11 & 2233.4 & 2216.8 & 1631 & 1547.0 & 1354.7 & 1311.8 & 1262.9 \\
0.22 & 2233.4 & 2214.0 & 1633 & 1547.0 & 1354.7 & 1313.2 & 1258.7 \\
0.43 & 2232.8 & 2212.8 & $1636 / 1618$ & 1547.5 & 1354.4 & 1256.7 \\
1.0 & 2233.0 & 2213.0 & $1635 / 1615$ & & 1340 & 1257.0 \\
\hline
\end{tabular}

${ }^{\mathrm{a}} \bar{\nu}_{\mathrm{s} 1}\left(\mathrm{NO}_{2}\right)$ : symmetric stretching vibration of the "free" $o-\mathrm{NO}_{2}$ group. ${ }^{\mathrm{b}} \tilde{\nu}_{\mathrm{s} 2}\left(\mathrm{NO}_{2}\right)$ : symmetric stretching of the hydrogen bonded $o-\mathrm{NO}_{2}$ group. 


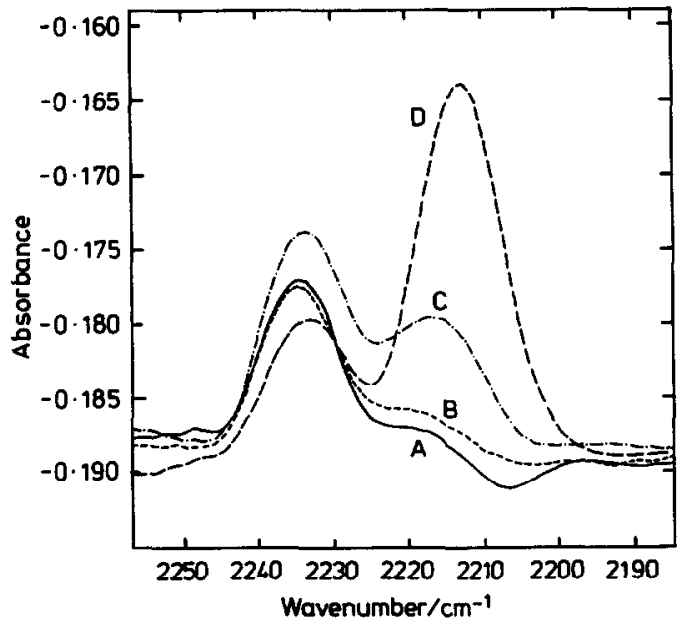

Fig. 15. Infrared spectra of the $\bar{\nu}(\mathrm{CN})$ band of 4CN26DNP in different benzene-DMSO mixtures. The mole fractions of DMSO are (A) 0.01 , (B) 0.06 , (C) 0.22 , (D) 0.42 .

positions relative to the $\mathrm{OH}$ group. Both the breaking of the intramolecular hydrogen bond and the ionisation lead to solvated species which may allow the two ortho-nitro groups to recover planarity with the aromatic ring. This may provide the necessary energy compensation for the breaking of a stronger intramolecular interaction.

\section{Conclusions}

In non-polar solvents (benzene or dichloromethane) both isomeric phenols form strong intramolecular hydrogen bands and in the order expected from their $\mathrm{p} K_{\mathrm{a}}$ values (Scheme 1). There is good evidence in the case of the $4 \mathrm{CN}$ isomer that the two nitro groups are distinct and

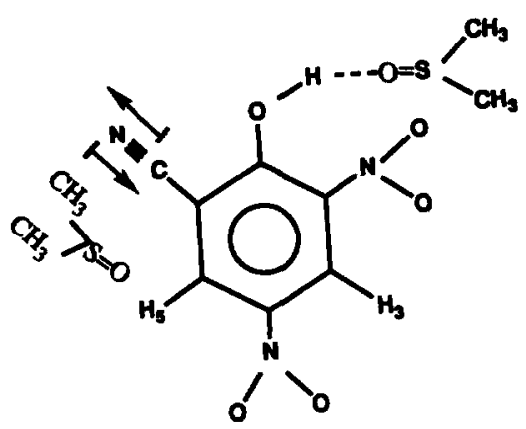

Scheme 7. therefore that there is no "delocalisation" of the hydrogen bonded interaction on the IR time scale. In protic solvents, such as methanol, the intramolecular hydrogen bonds are broken (more easily for the $4 \mathrm{CN}$ isomer) despite the intermolecular hydrogen bond being "weaker" (as measured from the $\tilde{\nu}(\mathrm{OH})$ band shift). This maybe due to relief of steric interactions which allow the $o-\mathrm{NO}_{2}$ group(s) to recover planarity with the aromatic ring. But it is also probably related to distribution of "solvation" interactions in protic solvents. In aprotic, but polar, solvents (such as DMSO) the $4 \mathrm{CN}$ isomer is progressively ionised producing the corresponding phenolate (and a protonated solvent molecule). However, the $2 \mathrm{CN}$ isomer remains in the neutral but highly solvated form, presumably due to the (relative) lack of energy requirements caused by steric congestion at the ortho positions.

SERC are thanked for equipment grants. We are also grateful to Junta Nacional de Investigacao Cientifica e Tecnologica, Portugal for a research studentship for P.C.M.F.C.

\section{REFERENCES}

1 V.M. Schreiber, J. Mol. Struct., 197 (1989) 73.

2 J.P. Hawranek and M.A. Broda, Z. Phys. Chem., 141 (1984) 159; Spectrochim. Acta, 43A (1987) 617; Chem. Phys. Lett., 98 (1983) 373.

3 A.E. Lutskii, Yu. I. Dolzhenko and A.J. Mitichkin, Zh. Obshch. Khim., 50 (1980) 2339, 2346.

4 T.N. Pliev, Izv. Vyssh. Uchebn. Zaved. Khim. Tekhnol., 30 (1987) 29; C.A., 108 (1988) 93972e.

5 J.P. Seguin, F. Guilhaume, R. Uzan and J.P. Doucet, J. Chem. Soc., Perkin Trans. II, (1986) 773.

6 S.F. Bureiko, M.S. Golubev, J. Mattinen and K. Pihlaja, J. Mol. Liq., 45 (1990) 139.

7 A.E. Lutskii, T.I. Klependra, G.G. Sheina and L.P. Batrakova, Zh. Prikl. Spektrosk., 25 (1976) 735.

8 V.A. Granzhan, S.V. Semenenko and P.M. Zaitsev, Zh. Prikl. Spektrosk. 9 (1968) 407; 12 (1970) 922.

9 S.F. Bureiko, M.S. Golubev and I. Ya. Lange, Kinet. Katal., 23 (1982) 209.

10 L.L. Shevchenko, A.T. Pilipenko and L.F. Dubina, Ukrain. Khim. Zh., 39 (1973) 930.

11 D. Brown, D.R. Clifford and D.A.M. Walkins, Pestic. Sci., 3 (1972) 551.

12 A. Pross and L. Radom, Prog. Phys. Org. Chem., 13 (1983) 1. 
13 R.D. Topsom, Prog. Phys. Org. Chem., 16 (1987) 85.

14 P.C.F.M. Castilho, M.R. Crampton and J. Yarwood, J. Chem. Res., Synop. (1990) 394.

15 H.L. Strauss and R. McPhail, J. Chem. Phys., 82 (1985) 1156; 87 (1988) 6665.

16 S. Bratos, G. Tarjus and P. Viot, J. Chem. Phys., 85 (1986) 803; J. Mol. Liq., 36 (1987) 185.

17 J. Yarwood, in J. Yarwood (Ed.), Spectroscopy and Structure of Molecular Complexes, Plenum, New York, 1973, Ch. 2.

18 M.S. Bayliss, A.R.H. Cole and L.H. Little, Spectrochim. Acta, 15 (1959) 12.
19 A.R. Katritsky and R.D. Topsom, Chem. Rev., 77 (1977) 639.

20 Borek, Naturwissenschaften, 50 (1963) 471.

21 L.J. Bellamy, Infrared Spectra of Complex Molecules, Vols. 1 and 2, Chapman and Hall, New York, 1980.

22 P.C.F.M. Castilho, M.R. Crampton and J. Yarwood, in preparation; P.C.F.M. Castilho, Ph.D. Thesis, Durham University, 1991.

23 G.A. Olah, A.T. Ku and J.A. Olah, J. Org. Chem., 35 (1970) 3904. 